\title{
TECNOLOGIAS EDUCACIONAIS: INOVAÇÃO E FORMAÇÃO DE DOCENTES
}

\author{
TECNOLOGÍAS EDUCATIVAS: INNOVACIÓN Y FORMACIÓN DEL PROFESORADO
}

EDUCATIONAL TECHNOLOGIES: INNOVATION AND TEACHER TRAINING

Christian Belanga da SILVA ${ }^{1}$

RESUMO: As tecnologias educativas colaboram na formação discente, e para isso é válido analisar o cenário, pois para isso, a formação docente para com o uso das TIC se torna essencial. Ao elaborar esta resenha, verificou-se de que de acordo com os autores, barreiras devem ser quebradas para que possa haver a aplicação das TIC em sala de aula. Para que isso aconteça, deve-se oferecer uma melhor qualidade de educação aos docentes, para que possam buscar metodologias adequadas e usufruir da tecnologia da nova geração para aulas participativas e reflexivas afim de transmitir o conhecimento entre aluno e professor.

PALAVRAS-CHAVE: Educação. Mediação. Tecnologia da Informação. Docência. Metodologias de ensino.

RESUMEN: Las tecnologías educativas colaboran en la formación de los estudiantes, y para ello es válido analizar el escenario, ya que para ello, la formación del profesorado para el uso de las TIC se vuelve esencial. Al redactar esta revisión, se constató que, según los autores, se debían romper las barreras para que las TIC se puedan aplicar en el aula. Para que esto suceda, es necesario ofrecer una mejor calidad de la educación a los profesores, para que puedan buscar metodologías adecuadas y disfrutar de la tecnología de la nueva generación para clases participativas y reflexivas con el fin de transmitir el conocimiento entre los estudiantes y Profesor.

PALABRAS CLAVE: Educación. Mediación. Tecnología de la información. Enseñanza. Metodologías de enseñanza.

ABSTRACT: Educational technologies collaborate in the training of students, and for this it is valid to analyze the scenario, because for this, teacher training for the use of ICT becomes essential. In making this review, it was verified that according to the authors, barriers must be broken so that ICT can be applied in the classroom. For this to happen, a better quality of training should be offered to teachers, so that they can seek appropriate methodologies and enjoy the technology of the new generation for participatory and reflexive classes in order to transmit the knowledge between student and teacher.

KEYWORDS: Education. Mediation. Information technology. Teaching. Teaching methodologies.

1 Faculdade Anhanguera de Bauru (FAB), Bauru - SP - Brasil. Graduando em Pedagogia. E-mail: christianbelangaaa@gmail.com 
Tudo no mundo se encontra em constante evolução devido aos avanços tecnológicos com o passar dos anos, e a educação, é claro, não fica de fora. Segundo o autor, é necessário que o docente consiga se adaptar a novos métodos de ensino frente a novas tecnologias de um modo que trabalhe também a autonomia do aluno.

Diante dos avanços, a questão que fica é: quais metodologias de ensino podemos desenvolver perante tais tecnologias de modo que a relação aluno e professor seja afetiva?

Um exemplo da situação é, o aluno tendo equipamentos com capacidade tecnológica suficiente para buscar informações on-line a qualquer momento através de um smartphone por exemplo, isso pode causar certa insegurança no docente. Para que isso não ocorra, precisamos pensar em métodos dos quais o professor possa fazer uso de tal tecnologia ao seu favor dentro da sala de aula.

Vale lembrar que, mesmo com o "mundo" em mãos, é indispensável a presença de um superior pois, além de ser a base do educar, é quem também faz e desenvolve o cérebro dos alunos, fazendo-os entrar em modo de reflexão e desativando o modo de robotização de suas rotinas.

Os autores dizem: "Nessa proposta da Sala de Aula Invertida o aluno é o centro e o professor passa a ser mediador". O que será que isso quer dizer? Em meu ponto de vista, é necessário esse tipo metodologia de ensino pois, desse modo o aluno toma uma responsabilidade maior e, consequentemente, carrega uma autonomia maior. Esse tipo de ensino fara ser necessário que o estudante tenha mais foco no aprendizado e que possa dialogar e refletir com seus colegas e professores sobre determinado assunto. Nesse caso, o professor passa a ser mediador, ou seja, apenas acompanha e discute sobre o que está sendo apresentado pelo aluno, dando-lhe total liberdade de expressão e ainda sim, agindo como um docente.

O que um profissional precisa para ter uma boa prática docente perante as novas TICs?

Antes de tudo, inovação é a palavra-chave. É preciso usar a tecnologia com fontes confiáveis e de forma crítica para reflexão. Pesquisas para reflexão tornam-se muito mais envolventes e interessantes quando é apontada por relatos de alunos, pois muitas 
vezes há uma ligação de informações que podem ser debatidas entre outros alunos e professores de forma crítica, abrindo assim um verdadeiro debate em sala de aula. $\mathrm{O}$ que quero dizer é: o docente é a base do educar, mas são os alunos que constroem seus próprios caminhos na aprendizagem. O professor é aquele que instrui, mas não pode controlar a cabeça dos estudantes, muito pelo contrário, deve ajudar a desenvolver a criatividade e capacidade de refletir de forma crítica sobre diversos assuntos e situações.

É indiscutível o fato de que estamos cada vez mais próximos de um mundo completamente digital, muito do que era necessário ser feito com certa condição, tempo e esforço hoje pode ser feito com apenas um toque. Chegando a esse ponto de conversa, podemos refletir sobre a seguinte questão: se temos tamanha tecnologia para acesso a informações através do uso da internet, por que temos que frequentar aulas presenciais?

A verdade é que o motivo é literalmente o que diz a questão. Ter em mãos tamanho universo de informação não significa que o indivíduo vai saber de como usufruir dessas novas tecnologias para o aprendizado. Muitas informações que estão na internet são publicadas por pessoas que podem, ou não, ter verdadeiro conhecimento sobre o assunto em questão. E mesmo que tenha, o aluno não terá opinião própria sobre o assunto uma vez que leu informações e conclusões saídas da mente de outra pessoa.

Querendo ou não, isso influencia os estudantes a terem atitudes mecanizadas e não autônomas. E o professor, como docente, deve evitar que isso aconteça de modo que esteja constantemente influenciando o aluno a refletir e despertar a criatividade.

Nos dias de hoje, é um grande desafio para os professores em lidarem com tais avanços e, inclusive, precisam fazer cursos para que possam se adaptar à tecnologia na sala de aula. Uma vez que os alunos, por serem de uma geração mais recente, normalmente apresentam maior conhecimento que os professores em relação a diversos usos da internet. O professor precisa sempre estar atualizado para que possa acompanhar o ritmo.

Quando um aluno toma responsabilidade de docente em uma sala de aula, é ele quem fica exposto a outros alunos com maior, menos ou até mesmo sem nenhum conhecimento digital. Quando isso acontece, o aluno percebe que nem todos são iguais, sempre haverá alunos que aprenderão de formas diferentes e não apenas pelo uso da 
internet. Até porque não são todas as pessoas que possuem condição financeira para ter internet no celular por exemplo, apesar de ser maioria.

Por esse motivo o professor deve estar sempre preparado, com planejamentos diferentes para criação de suas aulas.

Para que isso aconteça, o docente precisa estar se relacionando com grupos de outros profissionais, além de outros professores, e principalmente com alunos, deixando assim um pouco de lado a superioridade como mestre do conhecimento em sala. Como disse anteriormente, nem toda informação gera conhecimento, pois existem na internet muitas opiniões formadas que geram um padrão e que não geram reflexão. É nesse momento que o professor deve fazer intervenção, questionando aos alunos: Por que isso acontece? Como isso acontece? O que vocês pensam a respeito?

A formação do docente deve estar diretamente relacionada às questões de reflexão e busca de respostas e não relacionada a técnicas de ensino tecnicista nas quais informações criariam padrões estereotipados de informação para serem usados mundo a fora de forma trabalhista e mecanizada. Ele deve agir como mediador entre essas informações para exercitar a mente. $\mathrm{O}$ aluno pode buscar informações antes, durante e após uma aula, mas os questionamentos e dúvidas devem surgir durante a aula, quando o mediador deverá estar presente na sala de aula.

É por isso que o estudo das TIC é muito importante para uma boa prática docente contemporânea. Com o desenvolvimento da tecnologia e do uso da internet como um mediador da informação e transmissão de conhecimento, observa-se: será que os profissionais docentes estão realmente preparados para utilizar novos meios tecnológicos para planejamento de suas aulas com a finalidade de formarem cidadãos?

Com os avanços das TIC foi também possível o acesso imediato em tempo real, o que pode ser mais uma pedra no caminho para a formação docente, pois a qualquer momento informações podem não proceder ou serem atualizadas e o professor deverá estar sempre atento as mudanças. Para que isso seja reforçado, muitas das especializações, em nível de pós-graduação, envolvem principalmente o uso das Tecnologias da Informação e Comunicação.

Os autores citam Perrenoud, o qual aponta as TIC como contribuição para novos métodos inovadores e maneiras de trabalhar, na tomada de decisões, no ato de pensar, 
assim como nas formas de comunicação e o ato de comunicar-se. O que se entende disso é que o docente precisa de uma formação para saber como usufruir corretamente dessas novas TIC, uma formação voltada a utilizá-las. Cabe ao professor decidir qual tipo de formação usar para metodologias diferentes de suas aulas, muitas vezes o docente fica em dúvida quanto a essa questão.

Nos últimos anos, a preocupação com a formação dos professores perante as novas TIC tem aumentado gradualmente, tornando-se um assunto um tanto quanto delicado quando relacionado a metodologias novas de planejamento com novos recursos tecnológicos. Mudanças estão constantemente sendo feitas como consequências das novas tecnologias como: mudanças na sociedade, cultura, econômica e política. Existe certa competitividade pelo saber, que está ligada a uma educação de qualidade. $\mathrm{O}$ que isso quer dizer? Não há uma resposta certa ou errada para essa pergunta, pois é na verdade uma questão sobre a qual devemos refletir.

É claro que todos nós queremos e temos o direito de uma educação de qualidade, mas não há um modelo fixo de como usar as TIC para que todos saiam felizes e com um bom aprendizado, transmitido pela tecnologia e mediado pelo professor. É nisso que estamos refletindo nessa resenha, é exatamente isso, como podemos usufruir dos recursos hoje, para aplicá-los na educação de forma que agrade a todos e que apresente bom desempenho.

Os autores, ao citarem Ferenc e Mizukami, relatam o que diz respeito a como a formação do professor para a docência torna-se um campo de pesquisa constante de práticas pedagógicas, pois sempre estamos tentando buscar respostas que resultam no bom uso das TIC. A metodologia do Ensino superior em conjunto com a disciplina de Tecnologias Educacionais pode instruir as habilidades necessárias para o manuseio e a interação das TIC, gerando assim reflexões críticas entre a informação e o conhecimento.

De acordo com a LDB - Lei 9394/96 em relação com processo de formação dos profissionais para a docência, é um tanto quanto tímida conforme o artigo 66 diz: "A preparação para o exercício do magistério superior far-se-á em nível de pós-graduação, prioritariamente em programas de mestrado e doutorado". Percebemos na frase, que não 
há uma exigência pedagógica mencionada, pois são formações com perspectiva de pesquisadores.

Diante de toda essa discussão, é claro que não podemos dizer que qualquer docente possa fazer um bom uso das TIC em aula apenas por ter um mestrado ou doutorado, mas sim o que elas realmente oferecem para preparar por exemplo, as disciplinas como a didática.

Nesse aspecto, os conteúdos podem ser virtuais, mas também devem ter um peso presencial em sala de aula, tanto na prática quanto na teoria. Isso facilita o processo de mediação do professor em convivência com os alunos, independente de culturas ou experiências diversas, com ou sem acesso as tecnologias de última geração.

\section{REFERÊNCIAS}

SANTOS CRUZ, José Anderson; BIZELLI, José Luís. Tecnologias educacionais: Inovação e formação de docentes. Cad. Ed. Tec. Soc., Inhumas, v. 5, p. 258-266, 2014. ISSN 2316-9907 (Online). DOI 10.14571/cets.v5.258-266.

\section{Como referenciar este artigo}

SILVA, Christian Belanga da. Tecnologias educacionais: inovação e formação de docentes. Temas em Educ. e Saúde, Araraquara, v. 15, n. 1, p. 180-186, jan./jun. 2019. e-ISSN 25263471. ISSN 1517-7947. DOI: 10.26673/tes.v15i1.12772

Submetido em: $10 / 12 / 2018$

Aprovado em: 10/02/2019 